\title{
JESÚS Y LA REHABILITACIÓN DE LAS VÍCTIMAS DE ABUSOS
}

Jesus and the Rehabilitation of the Victims of Abuse

Jorge Costadoat *

RESUMEN: Este artículo asume la tarea de hacer teología sobre la realidad de las víctimas, especialmente de las personas abusadas sexualmente. Su intento es delicado porque cualquier discurso sobre las víctimas y el mal en general corre el riesgo de justificar lo injustificable. Esto sucede exactamente las veces que se exalta la importancia que tiene la cruz para la salvación de los pecadores, pero se olvida la historia del Jesús que murió asesinado por ofrecer una liberación, en primer lugar, a las víctimas de los pecados. El texto ofrece una comprensión de Cristo como víctima que ayuda a rehabilitar a las víctimas y a impedir que nuevas personas padezcan lo que estas padecieron. Asimismo, resalta la importancia teológica de ellas pues a través de las personas abusadas es posible llegar a saber que Dios es liberador y que el cristianismo, hasta donde podemos entenderlo, es solidaridad con los inocentes.

PALABRAS CLAVE: Víctimas. Abusos sexuales. Significado de la cruz. Cristo liberador.

ABSTRACT: This paper is a theological study about the reality of victims, especially those who have suffered sexual abuse. This is a sensitive issue because any talk about victims and evil in general risks justifying what is unjustifiable. When such a justification is carried out by exalting the importance of the cross for the salvation of sinners, one forgets the story of Jesus who was assassinated due to his offering of liberation to those who were victims of sins. This paper provides an understanding of Christ as a victim and contributes to rehabilitating victims

\footnotetext{
* Pontificia Universidad Católica de Chile, Santiago de Chile, Chile.
} 
in general, so as to prevent more people from suffering that which the victims have already suffered. Besides, this article highlights the theological relevance of victims as, through the people who have suffered abuse, it is possible to become aware that God is liberator and that Christianity demands solidarity with those who are innocent.

KEYWORDS: Victims. Sexual Abuse. Meaning of the Cross. Christ the Liberator.

\section{Introdução}

L a revelación pública de los abusos sexuales del clero y su encubrimiento contecida en los últimos años ha hecho entrar a la institución eclesiástica en una crisis que remece sus cimientos (SCHICKENDANTZ, 2019) ${ }^{1}$. Los informes y estudios del fenómeno se multiplican porque son muchos sus aspectos. Mucho más se dice de los escándalos en las redes sociales. Evidentemente que en estas el lenguaje suele ser irresponsable, pero a veces se expresan en ellas experiencias que las publicaciones científicas deben tomar en serio. Este es el caso de los siguientes tweets:

"Soy sobreviviente y mujer trans no me sirve de nada un libro teológico no creo, quiero justicia, verdad y reparación al igual que centenares de sobrevivientes" $^{\prime 2}$

“Claro amigo, pero qué difícil es, quieren más relatos desgarrados... ¿más morbo? Para entender que esto no es teoría ni teología ni fe... esto es delito:

\footnotetext{
${ }^{1}$ Este texto se enmarca en el proyecto de investigación Fondecyt № 1190556 (Chile). SCHICKENDANTZ, C. El estatuto teológico de la Palabra de Dios en los acontecimientos históricos actuales: articulación entre principios teológicos y datos empíricos. Disponible en: <https:// www.academia.edu/43442628/Proyecto_Fondecyt_Regular_N_1190556_El_estatuto_teol\%C3\%B3gico_de_la_Palabra_de_Dios_en_los_acontecimientos_hist\%C3\%B3ricos_actuales._Articulaci\%C3\%B3n_entre_principios_teol\%C3\%B3gicos_y_datos_emp\%C3\%ADricos $>$. PDF. Descripción del proyecto: En los debates conciliares con ocasión de la formación de Gaudium et spes se hizo visible para varios de los teólogos que estaba en discusión una forma de proceder nueva en razón de la introducción del momento inductivo que se postulaba. Este método llegó a impactar significativamente la pastoral y las teologías en nuestro continente. De Medellín en adelante, el método ver-juzgar-actuar se tornó emblemático en la Iglesia y en la teología en América Latina. La primera línea de trabajo de esta investigación se refiere a lo que puede calificarse como la densidad teológica del presente, a la articulación del momento empírico-inductivo con los llamados principios teológicos. La segunda línea de trabajo atiende al desarrollo que esta problemática ha tenido en la bibliografía latinoamericana, expresada en el uso de los conceptos de lugar teológico y de revelación. La tercera línea de trabajo problematiza sobre la inclusión de la investigación cualitativa en el momento empírico del método teológico.

${ }^{2}$ TERESA. Soy sobreviviente y mujer trans no me sirve de nada un libro teológico no creo, quiero justicia, verdad y reparación al igual que centenares de sobrevivientes. 12:13 AM · 14 de mar de 2019. Twitter: @lagatacombativa. Disponible en: <https://twitter.com/lagatacombativa/status/1106030501679255552>. Acceso en: 14 mar. 2019.
} 
mentir con sotana y violar, indulgencias plenarias después de confesar SU abuso y yo culpable, sin vida, un zombi por años"3

Los teólogos sabemos de una teología negativa, a saber, de un discurso sobre lo que no-es Dios: mortal, finito, cognoscible, pasible. Pero, ¿es Dios impasible? (SEGUNDO, 1984, p. 309). Los teólogos latinoamericanos han creído que la teología negativa tiene que ver exactamente con una pasión, la de Jesús y la de todas las víctimas inocentes: nada debiera decirse acerca del significado de la cruz a no ser que sea para evitar que los sufrimientos de las víctimas continúen ocurriendo. Bajo este respecto, en América Latina se ha replanteado el tema de la teodicea (SOBRINO, 1999, p. 273).

El objeto de este artículo es vincular a Cristo, la víctima por excelencia para los cristianos, con las víctimas que hoy nos conmueven, despejando para ellas la posibilidad teológica de su rehabilitación, posibilidad que lamentablemente ha sido negada por la misma teología cristiana y la Iglesia institucionalmente considerada. La motivación inmediata es hacerse cargo del sufrimiento injusto de los y las inocentes con una respuesta evangélica.

En la primera parte de esta publicación se explicará en qué sentido puede hablarse de Cristo cómo víctima. En la segunda, se considerará la importancia que tienen las víctimas para la liberación de los seres humanos en su conjunto, para el conocimiento del Dios de Jesús y para la espiritualidad cristiana.

\section{Cristo como víctima}

Dice san Juan: "Los soldados, después que crucificaron a Jesús, tomaron sus vestidos, con los que hicieron cuatro lotes, un lote para cada uno, y la túnica" (Jn 19, 23). Los crucificados eran expuestos desnudos a la mirada de quienes, de este modo, podían reírse de ellos. La pena de crucifixión incluía un escarnio sexual (GNILKA, 1983, p. 379-380).

En el cristianismo Cristo es la víctima por excelencia. Por extensión, las demás víctimas de la vida, de la sociedad y de la historia merecen una atención teológica (SOBRINO, 1999). Cabe preguntarse: ¿Qué relación existe entre esta víctima, Cristo, y las demás víctimas?

\footnotetext{
${ }^{3}$ INÊS. Cuando J Baeza (excura abuso sex conmigo y mi hmna) se veía descubierto por mi instinto de supervivencia: yo le decía papi: esto q hace está mal ;el me decía : hija" t lo juro por el Espíritu Santo q no se que me pasa contigo y t sabes q si juro por el Espíritu Sant es excomunión. Twitter: @SilbonitaB. 13 de mar de 2019. Disponible en: <https://twitter.com/ SilbonitaB/status/1105927207120224260>. Acceso en: 3 mar. 2019.
} 
Para responder a esta pregunta se hace necesario saber en qué sentido Cristo es víctima. ¿Víctima de qué? ¿De quién? ¿Por qué? En adelante se criticará la noción dolorista del sacrificio de la cruz. Y, a continuación, se explicará que el sentido del sacrificio de Jesús es su amor extremo e incondicional.

\subsection{El sacrificio del Hijo de Dios en la liturgia}

Antes de entrar en el tema del sentido de la cruz, me parece importante advertir primero que ha habido de ella interpretaciones erróneas o equívocas (DALY, 2009; GUNTON, 1994; SESBOÜÉ, 1990). Este sentido es posible hallarlo en los loci theologici, pero en ninguno de ellos es evidente. Se hace necesario relacionar unos con otros y, al menos, hacerlo con la Sagrada Escritura.

En este apartado se tomará como ejemplo de una posible mala interpretación del sentido de la cruz la Plegaria eucarística III (MISAL ROMANO), uno de los loci: a Eucaristía es memoria del sacrificio de Jesús. El Hijo de Dios fue víctima de una crucifixión que, por no merecerla, Dios la convirtió en causa de redención de los pecados y de salvación eterna. El problema es que, en la medida que los textos litúrgicos no mencionan la historia de Jesús o la dan por conocida, pueden llegar a trastocar su significado teológico.

Esto dice la Plegaria eucarística III sobre el sacrificio de Cristo como víctima:

"Así, Padre,

al celebrar ahora el memorial

de la pasión salvadora de tu Hijo,

de su admirable resurrección y ascensión al cielo,

mientras esperamos su venida gloriosa,

te ofrecemos, en esta acción de gracias,

el sacrificio vivo y santo.

Dirige tu mirada sobre la ofrenda de tu Iglesia,

y reconoce en ella la Víctima

por cuya inmolación quisiste devolvernos tu amistad,

para que, fortalecidos con el Cuerpo y la Sangre de tu Hijo

y llenos de su Espíritu Santo,

formemos en Cristo un solo cuerpo y un solo espíritu".

Es necesario analizar esta plegaria con cierto rigor. ¿Qué se nos dice? Se asocia el "sacrificio vivo y santo" de la Eucaristía con la "pasión salvadora" del Hijo de Dios. Lo que se realiza en el presente, con la intención de agradecer a Dios, parece guardar relación con un hecho que ocurrió en el pasado. No se aclara en qué consistió este evento. Sabemos, al menos, que este ha sido un hecho feliz porque trae la salvación. 
Si se toman en cuenta los otros elementos de la oración es posible precisar que este mismo hecho, revivido en el presente, también tiene relevancia salvífica futura para quienes "ofrecen" el Hijo al Padre. No obstante, se plantean otras dos dificultades. No se dice nada acerca de qué tipo de "sacrificio" se trata. Se supone que quienes participan en la Eucaristía lo saben. ¿Y si no lo saben? La asociación entre la "pasión salvadora" del pasado y el "sacrificio vivo y santo" del presente es dado por supuesto. Los partícipes en la Eucaristía debieran entender de qué "pasión" se habla pero, a decir verdad, no se dice una palabra acerca del motivo histórico de esta pasión.

En la segunda sección de la oración se sostiene que el Hijo de Dios es la "víctima". La "inmolación" de esta víctima devuelve la amistad con Dios. La acción eucarística se realiza para agradecer esto y para conseguir la unidad de la Iglesia. Aquí son de considerar dos asuntos. Primero, ahora sabemos que este es el sacrificio de una "víctima", con lo cual se confirma que se trata de alguien que ha experimentado una "pasión". Esta pasión, entendemos ahora, es resultado de una "inmolación". La víctima ha sido muerta, al modo como se ha matado animales o a seres humanos a lo largo de la historia sacrificándolos a una divinidad o ella misma ha ofrecido voluntariamente su vida. "Inmolación" es hoy una palabra usada para referirse a los terroristas que deliberadamente pierden la vida por una causa religiosa. El ícono de inmolación de nuestros tiempos son los pilotos de Al Qaeda que encajaron sus aviones en las Torres Gemelas de New York.

¿De qué habla la Plegaria eucarística III? Solo sabemos que se trata de un hecho de sangre, pero no mucho más. El Hijo de Dios pudo ser alguien matado como un animal o una especie de fanático religioso que se lanzó a quema ropa contra los opresores de su pueblo.

Continúa la plegaria eucarística:

“Te pedimos, Padre, que esta víctima de reconciliación traiga la paz y la salvación al mundo entero".

Unido a lo anterior, podemos agregar que el asesinato o inmolación voluntaria de esta víctima debiera servir para que el Padre del Hijo "traiga la paz y la salvación al mundo entero", y no solo a la Iglesia que celebra la eucaristía. No se trata de un acto mezquino de una secta que invoca el nombre de Dios para obtener privilegios particulares. Pero, en su conjunto, esta plegaria eucarística deja en la penumbra la historia del personaje salvador, el Hijo de Dios y, más aún, deja abierta la posibilidad de, tenido en cuenta el estudio comparado de las religiones, creer que pueda ser grato a Dios un acto sangriento.

No se dice que este Hijo de Dios sea Jesús. ¿Es verdaderamente hombre este Hijo de Dios? Nada se cuenta del reino al que Jesús dedicó su vida 
y por el cual lo mataron. Toda su historia, parece, tendríamos que darla por supuesto. Pero, al no aclararse de qué realmente habla la plegaria eucarística, la interpretación del sacrificio de esta víctima queda entregada a la posibilidad de no entender lo principal que, sin embargo, conocemos por vía de las Escrituras: el sacrifico cristiano consiste en el amor hasta el extremo (Jn 13, 1).

El Dios de los cristianos no necesita que le hagan sacrificios humanos para responder a la oración de los fieles (PICAZA, 2007). Su don es completamente gratuito. Es él mismo, como se insiste muchas veces en otros textos de la liturgia de la Iglesia, quien se ofrece en las ofrendas; la Iglesia no tiene nada que ofrecer a Dios que no haya recibido de Él. Jesucristo es el don que el cristiano presenta a Dios, porque es Dios mismo que se dona al ser humano. Pero la Plegaria eucarística III no habla del amor de Dios. A Jesús lo menciona en una petición secundaria. La plegaria olvida lo principal de Jesús como víctima y que San Juan resume en el recuerdo de la Última Cena: "Nadie tiene mayor amor que el que da la vida por sus amigos" (Jn 15, 13). René Girard, filósofo y sociólogo de las religiones, diría que muchos identificarían a Cristo con el chivo expiatorio que cataliza la violencia que amenaza con destruir a los seres humanos y que, muriendo en el lugar de todos ellos, reconcilia a la comunidad; siendo que, agregaría Girard, en Cristo se ha puesto al descubierto que no es necesario sacrificar seres humanos para que las comunidades, las sociedades o la humanidad sean liberadas de la violencia (GIRARD, 2002; MARDONES, 2007, p. 57-69). Estas debieran constituirse en base al amor. Esta sería exactamente la gran diferencia del cristianismo, su aporte más propio, en el contexto de las religiones sacrificiales.

Lamentablemente, en suma, la liturgia puede des-historizar a Jesús y dar pie para entender que la cruz, más que un símbolo de amor por las víctimas, es solo instrumento de perdón para victimarios y toda suerte de pecadores (PIO V; MISAL ROMANO, 2009). Ha sido necesario detenerse a analizar esta idea teológica de la cruz porque ella también está presente en otros ámbitos del cristianismo como, por ejemplo, en la espiritualidad. ¿Cómo experimenta a Dios un cristiano/a que es abusado/a? ¿Es para él/ella alguien que le pide resignación en la desgracia o es un Dios liberador?

\subsection{Jesús, víctima del reino}

El concepto de Jesús como víctima es peligroso. No es ningún peligro que alguien no entienda el lenguaje antiguo de las plegarias eucarísticas: sacrificios, expiaciones, holocaustos, inmolaciones, ofrendas, sangre y expresiones parecidas. Este lenguaje es hoy esotérico, críptico, aleja a la gente de las iglesias y, si a alguien atrae, probablemente sea a personas extrañas que andan buscando a Dios fuera de este mundo. Pero si alguna persona 
vincula este lenguaje a la noción de un dios que, para salvar, necesita que le sacrifiquen a un ser humano, ja su hijo!, la aplicación de esta idea en el campo de la vida cristiana puede hacer mucho daño. Si no se recupera la historia de Jesús, si no sabemos por qué lo mataron, su sacrificio se puede mover a resignarse ante la injusticia (SOBRINO, 1991, p. 26).

La plegaria eucarística recién analizada apenas identifica al Hijo de Dios con Jesús. La mención de la pasión, de la cruz o del Calvario, funge de mínimo de historicidad que asegura que el Hijo de Dios se encarnó y así, encarnado, pudo morir de muerte humana. Los ministerios de su vida no son considerados. Su historia, tal como nos es relatada por los evangelios, sobra o es dada por supuesta, es secundaria. Pero, ¿pudo entonces Dios encarnarse en un ser humano cualquiera con tal de morir como mueren los hombres? Sabemos que no, de ninguna manera. El salvador es Jesús, no el Hijo de Dios sin más.

\subsubsection{Jesús entrega su vida para que otros vivan}

Para entender lo anterior es preciso tener en cuenta tres entregas (BALTHASAR, 1980, p. 717-720) o sacrificios: la entrega de Jesús al advenimiento del reino de Dios, la entrega a la muerte ejecutada por sus enemigos y el donde Jesús de parte de su Padre en la cruz. Solo la recuperación de la historia completa de Jesús hace inteligible, hasta donde es posible, su sacrificio en la cruz.

Jesús entregó su vida para que el reino de Dios llegara. Él mismo se entregó (Jn 10,18). Se sacrificó o se inmoló, no porque su autodestrucción o una especie de masoquismo hasta la muerte pudiera ser grato a su Padre, independientemente del bien que hizo a las personas que amó.

El reinado de Dios que Jesús predicó y practicó como amor incondicional de Dios por todos, lo experimentó en primer lugar él mismo como hijo amado y lo hizo extensivo a los pequeños (Mt 11, 25-30). Esta misma experiencia de Dios le hizo acoger a las víctimas de los más diversos tipos de males y a otras víctimas que se acercaron a él buscando liberación de sus opresiones. Jesús anunció la prevalencia del amor actual de Dios en favor de las víctimas de los demonios, de las enfermedades, del menosprecio social y de las injusticias más diversas, y por vía de estas, en favor incluso de sus victimarios (Lc 23, 34). La Iglesia cree que la redención comenzó con el nazareno que consoló a los afligidos de sus dolores, que trató de aliviarlos y que los defendió de quienes pensaban que todos ellos merecían los males que padecían (Jn 9, 2).

Además, sabemos que Jesús fue entregado a la muerte por quienes lo mataron. Uno es el sacrificio voluntario de Jesús, otro el sacrificio de los que lo eliminaron (Mc 8, 31). Ambos sacrificios pretendieron un bien, pero 
bienes muy distintos. En el primer caso, hay que entender que la vida misma de Jesús en favor de los demás, todos sus gestos y palabras de compasión fueron un sacrificio. En el segundo caso, los escribas, fariseos y saduceos, las autoridades religiosas, al entregarlo a los romanos quisieron salvar la institucionalidad del Templo y de la Ley que ellos gestionaban y, por último, Pilatos, al entregarlo a la cruz, conjuró el peligro de una sublevación que habría sido indeseable para la pax romana. En todo caso, judíos y romanos no mataron a Jesús por ser el Hijo, sino por poner en peligro las instituciones con su desempeño inquietante. Jesús debió ser muy ingrato para las autoridades de Israel. El galileo cuestionaba la lógica de los sacrificios religiosos que los israelitas debían realizar en el Templo. Además, interpretaba la Ley como si él mismo la hubiera redactado. Los dirigentes del pueblo no podían tolerar que un judío cualquiera enseñara a las víctimas a cumplir con las exigencias del Templo y de la Ley con una extraordinaria libertad (DUQUOC, 1992, p. 67-76).

Jesús no se concertó con los jefes religiosos para ser sacrificado en Jerusalén. Jesús no se entregó a la muerte para colaborar con sus asesinos, de modo de configurar juntos una víctima dolorosa que trajera la salvación del mundo. A Jesús lo mataron contra de su voluntad. El no quiso ser víctima de nada ni para nadie. Solo deseó y procuró la vida de aquellos a los cuales precisamente se les menoscababa la vida. Él cumplió con la voluntad liberadora de su Padre. Una sociedad que necesitaba víctimas para funcionar -y qué sociedad no las necesita- no podía aceptar que alguien viniera a liberar a sus ciudadanos del sistema de convivencia tradicional.

El modo de comportarse de Jesús ante las instituciones de la Ley y del Templo resultó chocante para la oficialidad. Enseñó que la Ley se cumplía con solo amar a Dios y al próximo (Mt 22, 36-40). Sus palabras contra el Templo de Jerusalén y la expulsión de los mercaderes de sus atrios desafiaron a los sacerdotes para que entendieran que el sentido de los sacrificios era el amor gratuito. Jesús, al atacar el Templo, corazón religioso de Israel, liberaba de él al Dios que nadie debió nunca intentar comprar (Mc 11, 15-17). Jesús, con sus prácticas proféticas, anunció que Dios es gratis, que ningún sacrificio lo compra. El, con su amor subversivo, conmovió los cimientos de un mundo que no pudo soportarlo. El profeta de Nazaret desestabilizó la paz de Palestina. Caifás recomendó: "Conviene que muera uno por el pueblo y no que perezca la nación" (Jn 11,50). Pilatos lo entregó a la muerte, aplicándole la peor de las penas: la crucifixión. Jesús, en suma, fue un liberador, un sanador y un reparador de las víctimas (Lc 7, 36-50). Como consecuencia directa de esta praxis misericordiosa a lo largo de su vida, fue víctima de los sacerdotes y fariseos que consiguieron de los romanos colgarlo en una cruz. Dicho en breve, Jesús fue una víctima porque su causa fueron las víctimas. 
Por último, los evangelios nos dicen que Jesús se sintió abandonado por su Padre en la cruz (Mc 15, 33) (TAVARES, 1999, p. 162-169). ¿Cómo se entiende? Jesús no solo se entregó a sí mismo, no solo fue entregado a la muerte por sus victimarios, sino que fue entregado a la muerte por su propio Padre o, más precisamente, el Padre no hizo nada para librarlo de ella. Los evangelios dicen que antes de morir Jesús gritó a Dios (Mt 27, 50). ¿Fue este un grito desesperado? No sabemos, pero ciertamente ha sido el grito a Dios de tantas víctimas que, como él, se han sentido abandonadas por los demás e incluso por Dios mismo. ¿Puede haber algo más tremendo que no poder confiar más en la única persona en quien verdaderamente se ha podido confiar? Jesús, que en cierto sentido había hecho una apuesta en favor del Dios que escucha a las víctimas, justo cuando le tocó ser una de ellas no fue auxiliado por su Padre. Dios se ausentó. ¿No pudo su Padre hacerlo o estuvo de acuerdo con que lo mataran? ¿Necesitó que le crucificaran a su Hijo para salvar a la humanidad del pecado? ¿Se dio alguna rara complicidad entre el Padre y los crucificadores para hacer sufrir a Jesús y matarlo mediante torturas, para así cumplir la salvación? ¿Fue este el juego de las alianzas? Jesús, que corrió el riesgo de atacar a un sistema religioso que necesitaba y producía víctimas para operar, moría sin que Dios mismo acreditara el nuevo modo de relacionarse con él que Jesús encarnó, esto es, el del amor sacrificado y desinteresado por el prójimo.

En suma, Jesús no quiso su muerte más que como consecuencia última de su entrega para que los demás vivieran. Los que lo mataron no lo hicieron por esta razón, sino para salvar el sistema religioso que les hacía vivir a ellos a costa de los demás. Y el Padre de Jesús, en fin, ¿por qué quiso la muerte de Jesús? Entregó a la muerte a su propio Hijo. ¿Cómo se explica algo así?

\subsubsection{La peor de las interpretaciones de la cruz}

Las interpretaciones de la cruz son peligrosas (VÉLEZ, 2018, p. 186; SOBRINO, 1991, p. 284-285) pero, entre todas las posibles, la de la interpretación de la muerte vicaria y penal de Cristo es la peor de todas.

A este respecto, es necesario hacer una distinción. Durante los primeros mil años predominó en la Iglesia la visión griega de la salvación que ponía énfasis en lo que Dios hace por la redención de la humanidad (SESBOÜÉ, 1997, p. 113-132-316). A saber, Dios, en virtud de la encarnación del Hijo, gratuitamente nos hace hijos e hijas de Dios. A partir del segundo milenio, en cambio, comenzó a importar mucho más lo que los seres humanos hacen por alcanzar su salvación. En esta visión latina se acentuó que la redención, además de gratuita, ha de ser meritoria. Así, Jesús fue visto no solo como el don gratuito de Dios a la humanidad, sino sobre todo como el hombre que se dona a Dios y, por esto, merece la salvación de la humanidad condenada a la muerte por sus pecados. 
Este es el caso de San Anselmo. Por el año mil, el santo de Canterbury formuló la teología de la satisfacción (KASPER, 2006, p. 354s). Esta, en breve, postula que, puesto que es el ser humano quien debe reparar el honor de Dios herido por sus pecados, como Dios no ha debido absolver a la humanidad sin contar con ella para hacerlo, ha sido necesario que el Hijo de Dios, Jesús, hombre y Dios al mismo tiempo, realizara una vida humana y, como inocente, muriera en la cruz. Con esta explicación Anselmo habría querido conjugar la misericordia con la justicia de Dios. Sin embargo, en ella la salvación depende solo de la cruz. En Cur Deus homo (SAN ANSELMO, 1952, p. 739-894), la obra en la que desarrolla esta teología, la predicación y las acciones de Jesús como expresiones del reino, no cuentan casi para nada (GONZÁLEZ-FAUS, 1984, p. 492).

La teología sucesiva, de hecho, no reconoció valor teológico a la vida de Jesús anterior a la cruz. Con el paso de los años se acentuó en la Iglesia la noción de salvación como pago de Cristo por los pecados. Este pago fue entendido, a su vez, como castigo infligido a Cristo en lugar de los pecadores. Los flageladores de Jesús, sin saberlo, habrían ejecutado la voluntad del Padre de Jesús descargando en él la mayor violencia posible hasta matarlo para, por una parte, cumplir con la justicia divina y, por otra, otorgar la salvación. Bossuet, un teólogo del siglo XVII, llega a hablar de una venganza de Dios en la cruz:

"Era preciso que todo fuera divino en este sacrificio; era necesaria una satisfacción digna de Dios y era menester que Dios la luciera; una venganza digna de Dios, y que fuera también Dios quien la hiciera" (SESBOÜÉ, 1988, p. 82).

Continúa su descripción dramática del evento:

“Figuraos, pues, cristianos, que todo cuanto habéis escuchado no es más que un débil preparativo: era menester que el gran golpe del sacrificio de Jesucristo, que derriba a esta víctima pública a los pies de la justicia divina, cayera sobre la cruz y procediera de una fuerza mayor que la de las criaturas" (SESBOÜÉ, 1988b, p 83).

Según Bernard Sesboüé, a la base de este tipo de explicaciones sacrificiales de la muerte de Cristo ha operado el mecanismo psicológico de la compensación (SESBOÜÉ, 1997a, p. 117-118). Es muy propio de los seres humanos pensar que, dado un mal, debe haber un castigo o una reparación equivalente al mal hecho. En las ideas teológicas de la expiación, de la satisfacción y del sacrificio suele anidar esta idea de la compensación, llevando a olvidar que Dios es amor y que la verdad más profunda de la cruz es el amor gratuito del Hijo de Dios por los seres humanos.

¿Por qué la idea de una sustitución vicaria y penal de Cristo pudiera ser negativa o nefasta para las víctimas? Por de pronto, una noción de Dios justiciero y violento difícilmente puede ayudar a las víctimas de agresiones 
injustas. ¿Cómo pudieran creer ellas, personas traumadas por los abusos, que un Dios así las liberará de sus males? Tal vez alguna llegue a esperar que un Dios castigador se vengue contra sus abusadores. Pero, también es posible algo aún más terrible: que la víctima llegue a pensar que merece lo que sufre. Una espiritualidad que radique en una cristología masoquista conducirá a las personas a identificarse con el Cristo que sufrió porque Dios lo quiso directamente así y no como consecuencia del drama histórico del advenimiento del reino de Dios a los pequeños y a los últimos. Aún más dañino sería que las víctimas llegaran a confundir el bien y el mal y pensar, por ejemplo, que no son inocentes sino culpables, que sus victimarios han hecho lo que corresponde y que ellas, calladamente, deben aceptar la maldición que se les impone.

Desde un ángulo diametralmente opuesto, pensamos que el dolor de las víctimas acusa nada menos que a Dios mismo. Dios, si es amor infinito, no puede ser indiferente ante el sufrimiento inocente (GUTIÉRREZ, 1986 p. 18-19; TRIGO, 1988, p. 22-23; AZCUY, 2006, p. 14). Por tanto, dado que muchos inocentes sufren y mueren sin que Dios haga nada por liberarlos de sus males, su mera existencia finita y degradada lo cuestiona a Él mismo (SOBRINO, 1991, p. 354).

\subsubsection{Dios salva por medio de Jesucristo}

¿Qué puede decirse de un Dios que deja morir a su hijo en una cruz? ¿Necesita este Dios una religión que le organice sacrificios humanos para conceder favores a otros hijos suyos? ¿Para hacer llover o para perdonar los pecados? El cristianismo juega con fuego las veces que articula discursos sobre los sacrificios, las víctimas, los holocaustos y la sangre. La teología se vuelve peligrosa cuando pretende dar razón exhaustiva de la cruz. Pero, desde que Jesús murió crucificado, no puede no decir algo al respecto. Si la teología no ofrece ninguna explicación para la cruz, deja a las víctimas en la indefensión. Otros o ellas mismas, podrían ver algo supuestamente bueno en que se las haga sufrir como Dios dejó sufrir a Jesús. Algún bien habrá en esto, podrían decir. Si, por otro lado, se ofrece una explicación satisfactoria puede justificarse lo que no tiene justificación alguna. La cruz nunca debiera dejar de ser una acusación grave de las víctimas contra Dios.

El grito de Jesús en la cruz (Mc 15, 34) no debiera ser acallado nunca. La tradición cristiana, por esto, tiene que avanzar con sumo cuidado con las explicaciones teológicas: los cristianos debieran poder siempre levantar la cruz como protesta contra el sufrimiento injusto. Ella es símbolo de la reconciliación entre víctimas y victimarios las veces que esta protesta es acogida, cuando se pide el perdón y se lo da, pero no antes. Valga aquí la referencia a otro tweett: "Quiero justicia por las 150.000 víctimas en el 
mundo. No teología, ni Jesús en la cruz" (13 de marzo, 2019). Mientras no haya justicia, la invocación prematura del triunfo de la cruz insulta porque es banal.

Pero los cristianos creen que Dios salva a través de la cruz. Cristo muerto y resucitado es el salvador. La cruz, que puede ciertamente ser mal interpretada, constituye para ellos una condición fundamental de su salvación. El principio teológico del que depende la salvación y liberación de justos y pecadores, de víctimas y victimarios es la encarnación que concluye en el misterio pascual.

En primer lugar, hemos dicho que la cruz no solo fue querida por los asesinos de Jesús y que fue querida por él mismo como consecuencia inevitable de su coherencia. Ahora hemos de centrarnos en una convicción teológica aún más dura: la cruz de Jesús también fue querida por Dios su Padre. Por cierto, resulta desgarrador pensar que Jesús gritó a su Padre por haberlo abandonado y que el Padre no hiciera nada para librarlo de la cruz. Pero, ¿pudo evitarla? Si Dios es todopoderoso, ¿no pudo interrumpir el curso de los acontecimientos e impedir que los romanos lo torturaran y lo mataran? ¿Tuvo Dios las manos atadas que no lo impidió? ¿O es que Dios, por ser Dios, hace lo que se le da la gana? Es más, las Escrituras hablan de una cierta necesidad de la cruz (Lc 24, 26; 1 Pe 1, 11; Mc 8, 31).

A modo de respuesta, podemos sostener que el Dios de Jesús es de otro modo. En términos generales puede afirmarse que Dios no pudo evitar la muerte de Jesús porque Jesús, y no otro medio, ha sido su mediador de la salvación (1 Tim 2, 5). Como respuesta a las preguntas anteriores, ha de decirse que el Padre, al retraerse en el momento de la crucifixión de su Hijo, al no "meter mano" (TRIGO, 2010, p. 184) en los acontecimientos para arreglarlos a su amaño, hizo que toda la gesta de Jesús por el reino fuera verdaderamente humana, libre y meritoria. La historia del Hijo encarnado, su nacimiento y la inauguración del reino con hechos y palabras, señalan que Dios, para salvar, ha querido comprender la vida humana por dentro y salvarla sin paternalismos. De aquí que la recuperación de esta historia es decisiva, teológicamente hablando, para empeñarse en recuperar la historia de las víctimas. La Iglesia que escribió los evangelios para recordar el sentido de la cruz, debe hoy esforzarse en ayudar a las víctimas a hablar acerca de sus vidas y de los abusos padecidos.

Las víctimas necesitan que se crea en su relato porque su olvido exaspera su desgracia. Ellas quieren que se les crea. Pero les es riesgoso pedirlo porque la opinión pública puede castigarlas. Las víctimas, que deben poder pedir verdad y justicia en público, se expondrían una vez más al poder abusivo de los mismos que las silenciaron y que en la actualidad preferirían borrarlas para siempre, pues nada es más amenazante para los abusadores que la memoria passionis (METZ, 2007). Sería lamentable, 
por el contrario, que la Iglesia anuncie la salvación de los pecados, pero no los hechos liberadores de Jesús y la historia de quienes hoy podrían experimentar su liberación.

En segundo lugar debe entenderse que la resurrección es un acto de justicia y rehabilitación de Jesús de parte de Dios (BOFF, 1981, p. 153; SOBRINO, 1999, p. 129-130), ajusticiado injustamente. Es, por cierto, el triunfo de la vida sobre la muerte. Pero es el triunfo de este galileo concreto. La encarnación de aquel que termina siendo resucitado por Dios, no es la de un ser humano indeterminado. Nuevamente hay que decir que la historia de este ser humano es fundamental. La resurrección es un acto de justicia con Jesús. El Padre lo resucita por la misma razón por la cual Jesús vivió y por la que lo mataron. A saber, por haber predicado el reino a quienes se les niega la vida y la dignidad.

Dios se encarnó en Jesús. Jesús es fundamental para entender qué se entiende por Hijo de Dios y por Cristo. Por esto mismo, en la resurrección incluso podría decirse que Jesús "salva" a Dios. Hasta cierto punto se entiende que el Padre no haya intervenido en la historia de Jesús para no impedir que, como todo ser humano, hiciera un camino en libertad. Pero, de no haberlo resucitado, sabiendo lo que Jesús enseñó y por qué lo acusaron, el Padre habría quedado como culpable. Por cierto, muchas personas mueren clamando auxilio a Dios sin que Dios haga nada por consolarlas y salvarlas. Este dato debiera siempre recordarnos que Dios necesita -en cierto sentido- ser salvado. A partir de la resurrección, sin embargo, las víctimas tienen en el cristianismo un ofrecimiento de esperanza. Puede ser que ellas mismas mueran sin que Dios interrumpa el curso de la historia, sin que impida sus sufrimientos y sin poner a sus verdugos en el lugar que les corresponde. Pero tendrán la esperanza de que algún día todo saldrá a la luz, que se hará justicia y se comprobará que ellas tenían la razón y no quienes abusaron de ellas y luego las descalificaron y calumniaron.

Las víctimas, en virtud de su fe en la resurrección, ya ahora pueden caminar con la cabeza en alto y sacar fuerzas para vivir en un registro distinto del de los abusadores. Si la liturgia nos mueve a veces a pensar en un animal ofrecido en sacrificio, ha de tenerse presente que Jesús, la víctima, el Cordero, no es un simple ser humano que al ser resucitado vence a la muerte y a sus victimarios con su mansedumbre. Su triunfo es esperanza para víctimas que tienen un nombre y un apellido. Jesús alcanzó el triunfo de la resurrección porque antes fue víctima de hechos que nunca debieron ocurrir. En su condición de vulnerable y de víctima, solidario con los que sufren siendo inocentes, radica su autoridad. El Cordero del Apocalipsis es el Jesús vulnerable que, de pie al lado del Padre, con la marca de su pasión en el cuello, abre el libro en el que se revela el sentido de la historia a aquellas personas que vivieron y padecieron sin saber por qué (Ap 5, 
1- 4). Él es inocente, ellas también. La historia tiene sentido. El amor y la compasión con la humanidad sufrida y olvidada tienen la última palabra.

La resurrección de Jesús, por último, constituye el principio de reconciliación de la humanidad con Dios (Rom 11, 15) y, a propósito del tema que nos ocupa, de la reconciliación entre víctimas y victimarios. El triunfo de las víctimas no se verifica solo como justicia sobre quienes abusaron de ellas. Para ser plenamente cristiano, este triunfo solo será tal con una reconciliación que, si no se alcanza en este vida, puede al menos constituir un motivo de esperanza escatológica. Los victimarios también tienen un lugar en la salvación mediante un perdón que Dios ofrece a gratuitamente a todos. Como dice Pablo, "Cristo murió por los impíos; en verdad, apenas habrá quien muera por un justo; por un hombre de bien tal vez se atrevería uno a morir -; mas la prueba de que Dios nos ama es que Cristo, siendo nosotros todavía pecadores, murió por nosotros" (Rom 5, 6-8). Y continúa: "también nos gloriamos en Dios, por nuestro Señor Jesucristo, por quien hemos obtenido ahora la reconciliación" (Rom 5, 11).

Suele suceder que las víctimas no aceptan tan fácilmente algo así. La predicación de una reconciliación sin búsqueda de verdad y justicia en América Latina, por ejemplo, ha sido irritante para ellas y ha desprestigiado la palabra reconciliación. Esto no obstante, los cristianos saben que, en última instancia, no hay verdadera rehabilitación de las víctimas si estas no perdonan a su ofensores. Víctimas y victimarios, a los ojos de Dios, se requieren unos a otros reconciliados. No puede haber verdadero perdón si los victimarios no se arrepienten. Pero el arrepentimiento también depende de una oferta de perdón. Esto y lo otro requieren, en última instancia, de la reconciliación que tiene lugar en Cristo. En otra ocasión el mismo san Pablo exhorta a ella: "Cristo estaba Dios reconciliando al mundo consigo, no tomando en cuenta las transgresiones de los hombres, sino poniendo en nosotros la palabra de la reconciliación. Somos, pues, embajadores de Cristo, como si Dios exhortara por medio de nosotros. En nombre de Cristo os suplicamos: ¡reconciliaos con Dios!" (2 Cor 5, 19-20). Las víctimas no pueden ser forzadas a la reconciliación. Pero este es uno de los aspectos más importantes de la salvación (SESBOÜÉ, 407ss).

\section{Las víctimas como locus theologicus}

Hasta aquí hemos visto cómo se entiende que Cristo sea una víctima. Ahora veremos cuál es la importancia teológica que tienen las víctimas.

De lo anterior podemos concluir que, si la liturgia dijera algo más de la historia de Cristo cuyo sacrificio ella agradece en la eucaristía, conectando indisoluble y explícitamente la pasión del Hijo con el asesinato de Jesús, 
sería más fácil para los cristianos reconocer el valor teológico de la vulnerabilidad del ser humano y de las víctimas, y actuar en consecuencia. El caso es que en el cristianismo la relación de las personas abusadas, de las mujeres vejadas, de los hombres torturados, de las razas despreciadas, de los trabajadores explotados y de los que han sido dejados de lado sin posibilidad de trabajar con el Cristo humillado y sediento de justicia, debiera ser decisiva. Jesús se sacrificó a sí mismo por amor a aquellos que son sacrificados por los demás.

Las víctimas, en virtud de la víctima Jesús, tienen un valor teológico doble: por una parte, revelan quién es Dios y cómo salva y, por otra, cierran el camino a formas de espiritualidad inauténticas (individualistas, intimistas o masoquistas), a la vez que abren a un seguimiento de Cristo solidario con los abusados, silenciados y olvidados.

\subsection{Las víctimas pueden revelar a un Dios liberador}

Las víctimas son para los cristianos un locus theologicus (HÜNERMANN, 2014, p. 263-291). En ellas se encuentra a Cristo vulnerable-vulnerado como principio de conocimiento de Dios (COSTADOAT, 2018a, p. 231241; SOBRINO, 1999, p. 19-20, 319-320 ). Él, al liberarlas, puede revelar a Dios como liberador. Al igual que en Cristo, también en ellas puede realizarse el misterio pascual. Ellas son sacramentos de Cristo: todos los seres humanos pueden llegar a ser Cristo unos para otros que, como el Cordero inocente, merecen que se recuerde su historia, su verdad y su justicia como condición de perdón y de reconciliación entre ellos. Eso que la Iglesia llama salvación, es ya una realidad en el mundo. Esta salvación se actualiza toda vez que las personas vulnerables-vulneradas son reparadas (MONTERO, 2012, p. 235-242).

Pero este misterio no se cumple automáticamente. Las víctimas no revelan a Dios por el mero hecho de haber sido vulneradas. Ellas pueden perfectamente no creer que Dios sea bueno, no creer que el Padre haya hecho justicia a Jesús resucitándolo de la muerte ni que, dicho en términos seculares, algún día habrá justicia en el mundo. Esta increencia es muy legítima e, incluso, bajo cierto aspecto, sana. Ella ancla la creencia en Dios liberador en la libertad que pueden llegar a tener los seres humanos para decir a su Creador "no creo que seas un Dios de amor", "no me consta que me ames"; y, a los teólogos, "no me expliquen el significado de la cruz de Jesús". Si las víctimas no experimentan a Dios como liberador, abren en los seres humanos la noble posibilidad de no creer en Él y, a lo más, solidarizar con el Jesús que pudo morir decepcionado de su Padre. Si las víctimas no encuentran en Dios un auxilio y un defensor, pueden llegar a pensar con toda razón que Él mismo es un abusador, un cómplice o un encubridor. Solo las víctimas que experimentan al Dios compasivo en quien 
creen los cristianos, revelan que él es un Dios digno de fe. Ellas pueden ser mediadoras de la gracia (SOBRINO, 1999, p. 477). Lo dice una de las víctimas en uno de los tweet a los que he aludido: "Los sobrevivientes de abuso, tortura o maltrato somos mujeres y hombres al estilo de Jesús herido, muerto y resucitado" (12 de marzo, 2019).

Nadie tiene más autoridad para hablar del resucitado que las personas que han hecho esta experiencia. De modo semejante, los discípulos de Cristo, víctimas inocentes bajo algún respecto, se anunciaban unos a otros: "Dios resucitó a Jesús de entre los muertos" (Mt 27, 64). Esta generación probablemente escribió los evangelios para recordar lo que había ocurrido con Jesús, pues de lo contrario creer en un hombre crucificado habría podido llevar a sacralizar a las víctimas para exculpar a sus verdugos. El caso es que también hoy hay víctimas cuya fe las ha salvado. Lo afirma así otra víctima en las redes sociales:

“Mi fe intacta por cinco años me hizo creer que si realmente juraba por [el] Espíritu Santo era porque decía la verdad: No, abusaba de mí, de mi hermana y dejó embarazada a una joven del grupo juvenil de la parroquia. No me robó la fe, iyo abrí mi vida a una vida de verdad!" (13 de marzo, 2019).

Estas palabras merecen el mayor de los respetos. Ninguna explicación teológica puede ir más lejos que una declaración creyente de este tipo. Esta constituye el rudimento de la fe a partir del cual el cristianismo siempre debiera recomenzar. Ella actualiza la realidad del Cristo resucitado de pie junto al Padre que derrota a sus enemigos con su inocencia; aquella mujer es el Cordero que lleva una marca en su cuello como recuerdo de una historia que nunca debe olvidarse (Ap 5, 6).

En todos los casos de abuso debe admitirse la posibilidad de que las víctimas no lleguen a experimentar al resucitado. Y, sin embargo, los demás también pueden legítimamente esperar que esta gracia algún día les sea concedida. La solidaridad humana impide que unos se desentiendan de la mayor realización posible de sus prójimos. Oír el relato de las personas abusadas no debiera apagar en los oyentes su anhelo de amarlas y recuperarlas. Si los cristianos creen que la redención es participación en el misterio pascual de Cristo, han de tratar a las víctimas como sujetos capaces de resucitar, de ser sanadas y, a su vez, de asumir la necesidad de redención de sus abusadores. Las víctimas merecen ser tratadas como personas capaces de perdonar. Su propia dignidad demanda este trato. Tal vez, ellas mueran en la rabia. Los demás, empero, han de reconocer que la dignidad de las víctimas es trascendente. Ellas no merecen que alguien dé por cerradas sus vidas antes de tiempo.

Por otra parte, lo que no se puede aceptar es que las víctimas saquen provecho de su condición de tales. No por ser víctimas tienen la razón bajo cualquiera de los respectos. Nada debiera eximirlas de pensar, argu- 
mentar y reelaborar fatigosamente la convivencia social. Las víctimas son personas. Ser persona, en cuanto a esto respecta, requiere que todos se consideren seres dignos de perdonar y ser perdonados. Las víctimas son personas en relación a otras personas, y viceversa. Nadie puede forzarlas a interrelacionarse con sus abusadores ni con nadie. Pero no pueden impedir, si Dios no desespera del ser humano, que los demás esperen de ellas algo más.

\subsection{Las víctimas corrigen el camino de las espiritualidades}

En la Iglesia ha podido haber un estrecho vínculo entre la liturgia y la piedad. Entre ambas podemos imaginar que existe una conexión subterránea. La relación entre la liturgia que olvida la historia de Jesús, centrándose en su pasión salvadora y las espiritualidades intimistas que sobrevaloran la consagración eucarística y la hostia levantada sobre las cabezas de los fieles, es preocupante. Así como a las plegarias eucarísticas que insisten en la importancia del sacrificio de Cristo les vendría bien incorporar algo de la historia de Jesús, estas espiritualidades también se enriquecerían si se entendieran ellas mismas como seguimiento de Cristo. Lo que hasta ahora ha podido parecer el non plus ultra de la piedad cristiana, la mística del altar, puede constituir, bajo la óptica de las víctimas, la máxima traición al advenimiento del reino que Jesús anunció a ellas antes que a los asiduos al Templo. El cristiano, para ser tal, tendría que entender que, si su salvación no es la nuestra o la de todos los demás, la suya es una ilusión producida por la irreductible tentación de negar la historia que compartimos y disputamos con los demás y a lo largo del tiempo.

¿Por qué los cristianos, discípulos y discípulas de Jesús, hemos sido tan poco sensibles a las víctimas? Más aún ¿por qué hemos contribuido a la generación de un mundo de víctimas, silenciadas y olvidadas? ¿En qué momento sucedió que la religión originalmente de los perdedores se convirtió en la de los ganadores? Son demasiadas preguntas, más de las que corresponde responder aquí. Conviene al menos recordar que, al ser absorbida la Iglesia por Constantino en el siglo IV, los cristianos dejaron de ser martirizados. No fueron más perseguidos y humillados por los emperadores. Poco después, con Teodosio, el cristianismo revigorizó al Imperio con el triunfo de Cristo. Y, lamentablemente, la nueva religión, considerada a sí misma como la verdadera, propició la aniquilación del paganismo (JEDIN, 1980, p. 286-287). En la medida en que los cristianos accedieron al poder, ellos los perseguidos, se convirtieron en perseguidores. Desde entonces, en muchas áreas del planeta, hemos tenido un cristianismo colonizador (TAMAYO, 2017).

En el mismo siglo IV, y en reacción a esta deriva política y triunfalista de la religión imperial, se desencadenó en el cristianismo una fuga mundi, un apartarse del mundo (HONINGS, 1983, p. 155-156; LECLERCQ, 
1974, p. 53-67). Cristianos excepcionales, eremitas, anacoretas, monjes, quisieron reproducir en el desierto la suerte de las víctimas de los tres primeros siglos, pero ahora como mártires de persecuciones interiores del demonio. Las corrientes de espiritualidad vigentes hasta el día de hoy, las espiritualidades benedictinas, franciscanas, dominicas, jesuitas, las de las innumerables familias de vida religiosa femeninas, echan raíces, unas más, otras menos, en esta historia de confrontación monástica con el mundo. Miles, millones de cristianos, inspirados en estas espiritualidades, se han ocupado de curar a las víctimas de los más increíbles abusos. Pero, ¿cuántos de estos han querido atacar el fuego en la base? ¿Cuántos han dado la batalla política por erradicar las causas de los abusos? Un mundo sin víctimas es una utopía. Pero los cristianos han podido correr más riesgos para que nunca más un ser humano llegue a la tumba sin que nadie le haya hecho justicia.

Una re-comprensión del cristianismo debiera traducirse en correcciones en las espiritualidades intimistas, atemporales, alienantes y masoquistas, y abrírselo a experiencias de fe que asuman el penar de las víctimas individualmente consideradas o como colectividades atropelladas, silenciadas, intimidadas, culpabilizadas siendo inocentes y pisoteadas para pisotearlas. Una espiritualidad solidaria con las víctimas tendría que ser una espiritualidad valiente, martirial (BOFF, 1983). Sus sujetos tendrían que ser las mismas víctimas liberadas de la prepotencia de sus abusadores, y sus hermanos y hermanas cristianos sensibles a su realidad y dispuestos a sumarse a su lucha; tendría que convertirse en un impulso evangélico por la reconciliación. Una espiritualidad así tendría que ayudar a integrar a la comunidad a los marginados o auto marginados. La misma comunidad los necesita.

La lucha cristiana de las víctimas y por las víctimas tendría que permear la espiritualidad cristiana en general. La salvación viene del Cordero que, con su inocencia, desafió al Imperio romano. La salvación viene de las víctimas, no porque estas sean mejores que los demás, sino porque ellas son las primeras en experimentar la compasión de Dios. Solo un seguimiento de Cristo (COSTADOAT, 2016b) solidario con ellas redimirá a la Iglesia de su cobardía, de su alienación y de su complicidad con los que han invertido el significado de la cruz.

\section{Conclusiones}

Al terminar, presento algunas ideas conclusivas para continuar reflexionando en un tema que nunca debiera darse por pensado.

1 - El cristianismo tiene muchas deudas con las víctimas. El lenguaje religioso ha abusado de los términos sacrificio, holocausto, ofrenda, ex- 
piación, redención, sangre, culpa, perdón y reconciliación. Lo ha hecho cada vez que lo ha aplicado en favor del rescate de los pecadores sin tener en cuenta a las personas que han sufrido a causa de estos. A modo de ejemplo, hallamos en la liturgia católica algunos textos que parecen haber invertido el significado de la cruz. Estos acentúan que Cristo, la víctima por excelencia, redime el pecado del mundo, pero olvida que Jesús es el representante de todas aquellas personas que fueron atropelladas sin que sus historias llegaran a ser conocidas, muchas de las cuales, por lo mismo, murieron como culpables siendo inocentes.

Por otra parte, desde el momento en que el cristianismo se convirtió en una religión poderosa, legitimadora del poder político e ideológicamente conveniente a los señores de este mundo, bien parece que los cristianos se han vuelto cobardes para defender a las víctimas. Esta hipótesis tendría que ser probada. Pero no está de más recordar que la Iglesia solo ha respondido al reclamo de verdad y de justicia de las víctimas de abusos sexuales y de conciencia del clero gracias a la presión social mediatizada por la prensa y las redes sociales. Esta respuesta, cuando efectivamente la ha habido, ha sido lenta y forzada.

2 - Las víctimas tienen una doble capacidad de salvarnos. Primero, porque de ellas proviene la experiencia originaria de la salvación. Cristo resucitado es principio de rehabilitación de todas las víctimas de la injusticia. Estas, en la medida que hicieron una experiencia pascual de Dios, fundaron la Iglesia y anunciaron que Dios es liberador, no indiferente ante el sufrimiento humano. Esta experiencia empalma directamente con la predicación de las bienaventuranzas de Jesús. La predicación de la salvación como perdón de la humanidad pecadora es falaz si se aplica a cristianos individuales insolidarios de la suerte de víctimas inocentes como fue Jesús. Los mártires son los testigos por excelencia del cristianismo.

También la experiencia de las víctimas que no llegan a creer en Dios liberador, que no logran perdonar y que no esperan que haya algún día justicia en el mundo, es fundamental. Su reclamo contra Dios o contra la vida es legítimo y, en cierto sentido, necesario. Nadie merece lo que sufre y menos alguien que ha sido despojado de su dignidad. Ninguna explicación teológica debiera morigerar el grito de los seres humanos que no creen en un resucitado y a quienes Jesús no les dice nada. Él mismo, que murió gritando a su Padre, puede ser el representante de tanta gente que piensa que su vida no ha tenido sentido. Si los cristianos no llegan de alguna manera a hacer suya esta experiencia, su cristianismo no tendrá ancla en la vida de la humanidad a su nivel más profundo.

3 - La dignidad de las víctimas debiera constituir un principio clave de su reparación. El respeto de su dignidad exige esperar que esta reparación acontezca, pero también que ella no pueda forzarse. La condición 
de víctimas puede corromperlas. No por haber sufrido un abuso alguien debiera poder reclamar cualquier cosa de los demás. Este es, precisamente, un efecto posible, entre otros, de haber sido vulnerado en su dignidad. La propia dignidad, empero, es aquello que nadie debiera declinar. Si las mismas víctimas renuncian a ella, nadie tiene derecho a impedírselo ni a juzgarlas por ello.

Esto no autoriza, sin embargo, a quienes no han sido víctimas a desentenderse del prójimo que no puede perdonar ni quiere reconciliarse. Tratar a las víctimas con respeto exige no desesperar de la posibilidad de que su corazón se libere del trauma de las agresiones sufridas. El trato que las víctimas merecen demanda considerarlas personas que pueden más de sí mismas, aun cuando en la práctica no puedan dar más ni lo quieran. Ellas merecen que se confíe incondicionalmente en su dignidad y en su libertad. Necesitan fe, necesitan volver a creer. Solo lo podrán si se las espera.

\section{Referencias}

AZCUY, V. Teología e inequidad de género. Diálogo, interpretación y ética en el cruce de las disciplinas. In: BEDFORD, N.; GARCIA BACHMANN, M.; STRIZZI, M. (Eds.). Puntos de encuentro: foro sobre Teología y género. Buenos Aires: Instituto Universitario ISEDET, 2006.

BALTHASAR, H. U. von. El misterio pascual. In: FEINER, J.; LOHRER. M. (Dir.). Mysterium salutis: manual de teología como historia de la salvación. Madrid: Cristiandad, 1980. t. 3.

BOFF, L. Jesucristo liberador. In: BOFF, L. Jesucristo y la liberación del hombre, Madrid: Cristiandad, 1981.

BOFF, L. Reflexión sistemática sobre el martirio. Concilium, n. 183, p. 325-334, 1983.

COSTADOAT, J. Los pobres como lugar teológico. Dificultades con la conceptualización. Estudios Eclesiásticos, Madrid, v. 93, n. 364, p. 231-241, 2018.

COSTADOAT, J. Seguimiento de Cristo. In: DE MORI, G. (Org.) Theologica Latinoamericana Enciclopédia Digital. Disponível em: <https://theologicalatinoamericana. com/? p=1411>. Acceso en: 04 agosto 2019.

DALY, R. Sacrifice Unveiled: the True Meaning of Christian Sacrifice. London/New York: T\&t Clark international, 2009.

DUQUOC, C. Jesús hombre libre: esbozo de una cristología. Salamanca: Sígueme, 1992.

GIRARD, R. El chivo expiatorio. Barcelona: Anagrama, 2002.

GNILKA, J. Jesús de Nazaret: mensaje e historia. Barcelona: Herder, 1983.

GONZÁLEZ-FAUS, J.I. La humanidad nueva: ensayo de cristología. Santander: Sal Terrae, 1984. 
GUNTON, C. The actuality of atonement: a Study of Metaphor, Rationality an the Christian Tradition. Scotland: T\& T Clark, 1994.

GUTIÉRREZ, G. Hablar de Dios desde el sufrimiento del inocente: una reflexión sobre el libro de Job. Salamanca: Sígueme, 1986.

JEDIN, H. Manual de historia de la Iglesia. Barcelona: Herder, 1980. v. 2.

KASPER, W. Jesús, el Cristo. Salamanca: Sígueme, 2006.

HONINGS, H. Fuga. In: ANCILII, E. et al (Ed.) Diccionario de espiritualidad. Barcelona: Herder, 1983. p. 155-156.

HÜNERMANN P. El Vaticano II como software de la Iglesia actual. Santiago: Universidad Alberto Hurtado, 2014.

LECLERCQ, J. Mondo. In: PELLICCIA, G. (Dir.). Dizionario degli istituti di perfezione. Roma: Paoline, 1974. v. 6, p. 52-67.

MARDONES, J.M. Religión, cultura y violencia: la teoría mimética de R. Girard. Revista Anthropos: Huellas del conocimiento, España, n. 213, p. 57-69, 2007.

METZ, J. B. Memoria passionis: una evocación provocadora en una sociedad pluralista. Santander: Sal Terrae, 2007.

MISAL ROMANO. Plegaria eucarística III. Editado por la Conferencia episcopal argentina, Buenos Aires, 2009.

MISAL ROMANO. Prefacio de Pascua V. Editado por la Conferencia episcopal argentina, Buenos Aires, 2009.

PIKAZA, J. Victima, victimismo. In: Diccionario Enciclopédico de Biblia y Teología. Disponible en: <https://www.biblia.work/diccionarios/victima-victimismo/>. Acceso en: 04 agosto 2019.

PÍO V, Misal. Disponible en: <https://www.misas.org/sta.tic/descarga/ord_s. piov_la_es>. PDF

MONTERO, C., Vulnerabilidad, reconocimiento y reparación: praxis cristiana y plenitud humana, Santiago: Universidad Alberto Hurtado, 2012.

SAN ANSELMO. Cur Deus homo? In: Obras Completas. Madrid: BAC, 1952.

SCHICKENDANTZ, C. Fracaso institucional de un modelo teológico-cultural de Iglesia. Factores sistémicos en la crisis de los abusos. Teología y vida, Chile, v. 60, n. 1, p. 9-40, 2019.

SCHICKENDANTZ, C. El estatuto teológico de la Palabra de Dios en los acontecimientos históricos actuales: articulación entre principios teológicos y datos empíricos. Disponible en: <https://www.academia.edu/43442628/Proyecto_Fondecyt_Regular_N_1190556_El_estatuto_teol\%C3\%B3gico_de_la_Palabra_de_Dios_en_los_acontecimientos_hist $\%$ C3\%B3ricos_actuales._Articulaci\%C3\%B3n_entre_principios_teol $\%$ C3\%B3gicos_y_datos_emp\%C3\%ADricos>. PDF

SEGUNDO, J. L. Dos teologías de la liberación. Teología abierta. Madrid: Cristiandad, 1984. 3 v.

SESBOÜÉ, B. Jesucristo, el único mediador: ensayo sobre la redención y la salvación. Salamanca: Secretariado Trinitario, 1988. v. 1 y 2. 
SESBOÜÉ, B. Redención y salvación en Jesucristo. In: AA.VV. Salvador del mundo. Historia y actualidad de Jesucristo. Cristología fundamental. Salamanca: Secretariado trinitario, 1997.

SOBRINO, J. Jesucristo Liberador. Madrid: Trotta, 1991.

SOBRINO, J. La fe en Jesucristo: ensayo desde las víctimas. Madrid: Trotta, 1999.

TAMAYO, J.J. Teologías del sur: el giro descolonizador. Madrid: Trotta, 2017.

TAVARES, S. Il mistero della croce nei teología della liberazione latino-americani. Roma: Pontificium Athennaeum Antonianum, 1999.

TRIGO, P. El método teológico. In: AAVV. XXX años de itinerancia. Caracas: ITER, 2010. p. 135-230.

TRIGO, P. Creación e historia en el proceso de liberación. Madrid: Paulinas, 1988.

VÉLEZ, C. Cristología y mujer: una reflexión necesaria para una fe incluyente. Bogotá: Pontificia Universidad Xaveriana, 2018.

Artículo sometido en 04.08.2019 y aprobado en 30.03.2020.

Jorge Costadoat SJ es Doctor en Teología por la Pontifica Universidad Gregoriana (1993), profesor en lo Centro Teológico Manuel Larraín, Faculdad de Teología de la Pontificia Universidad Católica de Chile. Orcid: 0000-0002-3364-9899. Mail: jcostado@uc.cl

Dirección: Alameda 1869

Santiago

Chile 